\title{
Pediatric functional dyspepsia: A comprehensive review
}

\section{Dispepsia funcional en niños}

\section{Liz Febo-Rodríguez*}

Department of Pediatric Gastroenterology, Hepatology, and Nutrition, University of Miami, Miami, Florida, United States

\section{ABSTRACT}

Functional dyspepsia (FD) is a common but heterogeneous upper gastrointestinal disorder that causes recurrent and/or chronic epigastric symptoms, with an estimated prevalence in children between $3 \%$ and $27 \%$. Etiologies include genetic predisposition and events that cause disruption of the brain-gut-microbiota axis, such as environmental and psychosocial stressors, disturbance of the gut microbiota, and early life events that lead to hyperalgesia such as cow's milk protein. FD results in impaired quality of life and increased health-care costs, with an estimated $\$ 5$ billion in annual costs. Unfortunately, treatment options are limited given the complexity of its pathophysiology and the fact that most therapies are studied in adults and not children, thus making FD difficult to manage in pediatrics.

Keywords: Functional dyspepsia. Pediatric abdominal pain. Motility. Microbiome. Pharmacology.

\section{RESUMEN}

La dispepsia funcional (DF) es un desorden común del tracto gastrointestinal superior que causa síntomas epigástricos recurrentes y/o crónicos, con una prevalencia estimada entre 3\% al 27\%. Las etiologías incluyen predisposición genética y eventos que conllevan a la disrupción del eje cerebro-intestino-microbiota, tales como estresores del ambiente y psicosociales, disrupción de la microbiota intestinal y eventos en la vida temprana que llevan a la hiperalgesia, como la alergia a la proteína de la leche de vaca. La DF puede conducir a una calidad de vida deteriorada y con elevados costos de cuidado de salud, los cuales se estiman en unos \$5 billones anuales a nivel global. Desafortunadamente, los tratamientos disponibles son limitados dada la complejidad de la condición y que la mayoría de estos han sido estudiados en adultos y no en niños, lo cual dificulta el tratamiento pediátrico.

Palabras clave: Dispepsia funcional. Dolor abdominal en niños. Motilidad. Microbiota. Farmacología.

Correspondence to:

*Liz Febo-Rodríguez

E-mail: ljf17@med.miami.edu
NeuroGastroLatam Rev. 2021;5:144-153

Received in original form: 07-07-2021

Accepted in final form: 28-10-2021

DOI: $10.24875 /$ NGL.21000013

2462-7011/C 2021 Sociedad Latinoamericana de Neurogastroenterología, A.C. Published by Permanyer. This is an open access article under the CC BY-NC-ND license (http://creativecommons.org/licenses/by-nc-nd/4.0/). 


\section{INTRODUCTION}

Pediatric functional abdominal pain disorders are common, and they include functional dyspepsia (FD), irritable bowel syndrome, abdominal migraine, and functional abdominal pain not otherwise specified ${ }^{1}$. FD is a common but heterogeneous upper gastrointestinal (GI) disorder that causes recurrent and/or chronic epigastric symptoms, with an estimated prevalence in children between $3 \%$ and $27 \% \%^{2,3}$. FD prevalence has been increasing in recent years, and it is the second most common functional abdominal pain disorder after irritable bowel syndrome ${ }^{4}$. The pathogenesis for functional abdominal pain disorders is not clearly understood but numerous mechanisms have been implicated, including visceral hypersensitivity, delayed gastric emptying, psychosocial factors, dysfunction of the central nervous system, lifestyle factors, duodenal eosinophilia, and inappropriate gastric accommodation ${ }^{3,5-7}$. Impaired gastric accommodation is the most common documented abnormality in adult patients with FD, estimated at around $40 \%{ }^{8,9}$.

FD can be further subdivided into epigastric pain syndrome and post-prandial distress syndrome; however, these two syndromes can overlap in clinical practice ${ }^{10}$. Postprandial distress syndrome is characterized by symptoms that are triggered by a meal, including post-prandial fullness and early satiety ${ }^{3}$. Impaired gastric accommodation is thought to play a role in the postprandial distress syndrome group ${ }^{3}$.

There are currently no biochemical markers or structural abnormalities used to diagnose FD. A study by Singh et al. found the majority of children with a clinical diagnosis of FD lacked chronic or acute inflammation in the GI mu$\operatorname{cosa}^{11}$. However, $60 \%$ of children with FD have increased eosinophils in the antrum and duodenum (cutoffs of 10/high power field and 20/ high power field were used, respectively) ${ }^{11}$. The diagnosis of FD is clinical and based on the Rome criteria, which provides symptom-based guidelines by which children are diagnosed with functional GI disorders (FGIDs) $^{12}$. The most recent criteria, Rome IV, was issued in $2016^{13}$. Table 1 summarizes the Rome IV criteria used to diagnose FD.

The role of a diagnostic work-up, including labs and esophagogastroduodenoscopy (EGD) in pediatric FD, remains unclear. These patients tend to undergo extensive workup, with mostly minimal to no yield. The average cost per patient with functional abdominal pain disorder is around \$6,104 (range \$1,052$\$ 20,994)^{14}$. A study evaluating the charts of children $>4$ years of age diagnosed with abdominal pain showed that complete blood cell count was the most commonly done investigation $(92 \%)$, followed by a comprehensive metabolic panel $(83 \%)$, with electrolytes abnormal in only one patient (sodium: 132 $\mathrm{mEq} / \mathrm{L}), \mathrm{n}=122)^{14}$. In this same study, elevated inflammatory markers and celiac antibodies led to changes in in management in only five cases ${ }^{14}$. Unfortunately, most studies assessing the use of EGD in children with abdominal pain have had multiple limitations, including a small sample size, bias, and lack of standardization ${ }^{15}$.

The Rome IV pediatric committee does not believe there is compelling evidence to require an EGD in order to make a diagnosis of $\mathrm{FD}$, but does understand that physician 
TABLE 1. Rome IV diagnostic criteria for FD

Must include 1 or more of the following bothersome symptoms at least 4 days per month

1. Post-prandial fullness

2. Early satiation

3. Epigastric pain or burning not associated with defecation

4. After appropriate evaluation, the symptoms cannot be fully explained by another medical condition

Criteria fulfilled for at least 2 months before diagnosis. Within functional dyspepsia, the following subtypes are now adopted

1. Postprandial distress syndrome includes bothersome postprandial fullness or early satiation that prevents finishing a regular meal. Supportive features include upper abdominal bloating, postprandial nausea, or excessive belching

2. Epigastric pain syndrome, which includes all of the following: bothersome (severe enough to interfere with normal activities) pain or burning localized to the epigastrium. The pain is not generalized or localized to other abdominal or chest regions and is not relieved by defecation or passage of flatus. Supportive criteria can include (a) burning quality of the pain but without a retrosternal component and (b) the pain commonly induced or relieved by ingestion of a meal but may occur while fasting

Criteria fulfilled for at least 2 months before diagnosis.

practice patterns and social considerations may affect the decision to do one ${ }^{12}$. In addition, there are "red flags" that suggest further diagnostic work up should be done (Table 2) ${ }^{12}$.

\section{PATHOPHYSIOLOGY}

\section{Visceral hypersensitivity}

Visceral hypersensitivity is based on the strong association between the enteric nervous system and the central nervous system and their common embryonic origin ${ }^{16}$. Multiple factors predispose individuals to visceral hypersensitivity, including genetic, environmental, psychosocial (early stressors in life), and diet. These factors can alter the brain-gut axis communication by altering descending inhibitory control, impairing stress response, and/or sensitizing primary sensory neurons
TABLE 2. Potential alarm features in children with chronic abdominal pain

\begin{tabular}{l} 
Family history of inflammatory bowel disease, celiac disease, or \\
peptic ulcer disease \\
\hline Persistent right upper or right lower quadrant pain \\
\hline Dysphagia \\
\hline Odynophagia \\
\hline Persistent vomiting \\
\hline Gastrointestinal bleeding loss \\
\hline Nocturnal diarrhea \\
\hline Arthritis \\
\hline Perirectal disease \\
\hline Involuntary weight loss \\
\hline Deceleration of linear growth \\
\hline Delayed puberty \\
\hline Unexplained fever
\end{tabular}

and central spinal neurons ${ }^{16}$. This leads to abnormal secretion of excitatory neurotransmitters such as serotonin, which can result in changes in the central nervous system and trigger symptoms such as headache, abdominal pain, and discomfort ${ }^{16,17}$.

Early life events are known to be associated with the development of visceral hyperalgesia (cow's milk protein hypersensitivity, pyloric stenosis, umbilical hernia repair, and Henoch-Schönlein purpura) ${ }^{17,18}$. Rat models have shown that exposure to nociceptive somatic stimuli in the early neonatal period predisposes to visceral hyperalgesia, suggesting that disruption of the nervous system during its early development can alter the brain-gut axis, resulting in FAPDs ${ }^{17,19}$.

Carbone et al. used high resolution manometry to measure intragastric pressure in children and found that the intragastric pressure drop during 
meal ingestion in healthy and dyspeptic children was similar ${ }^{20}$. The authors suggest that increased sensitivity may be the reason why children with FD have decreased nutrient tolerance ${ }^{20}$.

Visceral and somatic endogenous pain modulations are central in fine-tuning and integrating pain perception ${ }^{21}$. They are closely integrated with affective, autonomic, cognitive, homeostatic, immune, and motor responses $^{21}$. FGIDs are associated with several factors that can lead to changes in these modulation pathways, including stress, anxiety, and chronic inflammation ${ }^{22}$.

\section{Altered GI motility}

Patients with FGIDs may present abnormal GI motility, leading to diarrhea, constipation, nausea, bloating, and distention ${ }^{17}$. As with visceral hypersensitivity, it is thought that early life events and psychological factors (e.g., abuse and hospitalizations) can lead to alterations in the gut microbiota that result in altered GI motility, including abnormal gastric myoelectrical activity, poor antral motility and gastric emptying and abnormal gastric accommodation ${ }^{17}$. In fact, multiple studies by Devanarayana et al. demonstrated that gastric emptying rate and antral motility parameters were significantly impaired in patients with Rome III criteria of functional abdominal pain, FD, and irritable bowel syndrome ${ }^{23-25}$. In addition, gastric emptying was found to negatively correlate with the severity of symptoms ${ }^{23,24}$. In another study led by Hoffman and Tack, children with FD were found to have slower gastric emptying than obese children $(89.7 \pm 54.8 \mathrm{~min}$ vs. $72.5 \pm 26.0 \mathrm{~min}$, $\mathrm{p}=0.05)$ using the octanoic acid breath test ${ }^{26}$.
These findings argue in favor of a role for GI motility disturbances in patients with FAPDs.

Gastric accommodation to a meal consists of relaxation of the proximal stomach without a concomitant increase in intragastric pressure $^{27,28}$. Inappropriate gastric accommodation is the most common documented abnormality in adult patients with FD, estimated at around $40 \%{ }^{8,9}$. Hoffman et al. assessed fundic accommodation in children with FD using the gastric barostat and found that $69 \%$ had inappropriate fundic accommodation ${ }^{29}$. Since the barostat test is invasive, few studies evaluating its use in children are available ${ }^{29}$. In children with FD, ultrasound imaging of the antrum has shown enlargement of the antral area, likely related to either inappropriate gastric accommodation or low antral tone ${ }^{30}$. Olafsdottir et al. showed that in children with recurrent abdominal pain, ultrasound revealed a smaller sagittal area and a higher emptying fraction of the proximal stomach $10 \mathrm{~min}$ after meal ingestion when compared to controls, likely due to inappropriate gastric accommodation ${ }^{31}$.

Children with FGIDs might also have abnormal gastric myoelectrical activity since muscular activity of the stomach is preceded by gastric electrical activity ${ }^{17}$. A study using electrogastrography found increased gastric electrical abnormalities in children with recurrent unexplained upper GI symptoms ${ }^{32}$. Further studies assessing these relationships are warranted.

\section{GUT MICROBIOTA}

The gut microbiome is recognized as a key player in the pathogenesis of functional 
abdominal pain disorders, including FD. The microbiome is composed of approximately $10^{13}-10^{14}$ microorganisms with 500 to 1000 different species ${ }^{33}$. Under non-stressful, normal circumstances, intestinal bacteria maintain a homeostatic relationship with the host muco$\mathrm{sa}^{34}$. However, alterations to this balance ("dysbiosis") can lead to enhanced intestinal permeability, mucosal immune activation, altered gut motility, and visceral hypersensitivity ${ }^{34}$.

\section{Psychological factors}

Children with functional abdominal pain disorders report a greater number of stressful experiences in the months before pain onset ${ }^{35}$. Common stress examples in children include failing an exam, separating from a best friend, loss of a parent's job, and/or moving to a new place $^{17}$. A recent study found that psychological stressors were the most common etiology for FD in children ${ }^{36}$. Abuse also predisposes to functional abdominal pain disorders, with one study showing that abdominal pain-predominant FGIDs were significantly higher in children who were abused sexually (34\%), emotionally $(25 \%)$, and physically $(20 \%)$ when compared to those who were not abused ${ }^{37}$. In addition, children with functional abdominal pain disorders are more likely to receive a diagnosis of a psychiatric disorder, including depression and anxiety ${ }^{38}$. Adult studies have shown that stress induces chronic overactivity or underactivity of adaptive systems, including the hypothalamic-pituitary-adrenal axis, autonomic nervous system, metabolic, and immune systems, which affects bodily function and behavior ${ }^{39}$. Thus, it is probable that stressful, adverse events in early life can result in long-lasting alterations in the brain-gut axis, leading to the development of functional abdominal pain disorders.

Children with chronic abdominal pain have also been shown to be less confident of their ability to change or adapt to stress ${ }^{40}$. In addition, mothers of children who suffer from functional abdominal pain were significantly more likely to have a lifetime history of IBS (odds ratio [OR], 3.9; 95\% confidence interval [CI], 1.510.3), anxiety (OR, 4.8; 95\% CI, 2.2-10.6), depressive (OR, 4.9; 95\% CI, 2.2-11.0), and somatoform (OR, 16.1; 95\% CI, 2.0-129.8) disorders when compared to mothers of controls ${ }^{41}$. Thus, how a child and family deal with stressors may be one of the key factors in chronic abdominal pain.

\section{ALTERED INTESTINAL PERMEABILITY}

The intestinal barrier includes surface mucus, epithelial layer, and immune defense ${ }^{42}$. Epithelial permeability can result from increased paracellular transport, apoptosis, or transcellular permeability ${ }^{42}$. Growing evidence indicates that increased intestinal permeability plays a role in functional abdominal pain disorders. Several entities are known to cause altered gut permeability, including infection, genetic predisposition, and stress ${ }^{43}$.

\section{HELICOBACTER PYLORI}

H. pylori bacteria have been associated with many diseases such as FD, gastric and/or duodenal ulcer, gastric cancer, and gastric mucosa-associated lymphoid tissue lymphoma ${ }^{44}$. However, most patients with $H$. pylori are asymptomatic. A meta-analysis evaluating symptom relief from $H$. pylori eradication in 
patients with FD found a small effect size; and found no improvement in the quality of life for patients with $\mathrm{FD}^{44}$. Eradication therapy was also associated with more side effects (vs. control). Thus, the decision to eradicate H. pylori should be individualized and preferred in patients with risk factors (i.e., peptic ulcer disease, gastric cancer, and Asian origin). A recent study in pediatrics found H. pylori to be present in $11 \%$ of the subjects with FD $(\mathrm{n}=55)^{36}$.

\section{Genetics}

Growing evidence has shown FD to be influenced by hereditary factors. Several gene polymorphisms have been studied in FD, including serotonin transporter promoter, interleukin-17F, migration inhibitory factor, cholecystocynine-1 intron 1, cychooxygenase-1, catechol-o-methyltransferase, transient receptor potential vanilloid 1 receptor, p22PHOX, Toll like receptor 2, SCN10A, CD14, and adrenoreceptors ${ }^{45}$. However, results are contradictory, mostly because of inconsistencies in the studies ${ }^{45}$. Further, assessments are needed, as there could be genetic contributions to FD.

\section{EPIDEMIOLOGY}

\section{Prevalence}

Based on the new Rome IV criteria, 25\% of infants and toddlers (0-3 years of age) and $25 \%$ of children and adolescents (4-18 years of age) met the criteria for one FGID ${ }^{46}$. In this same study, children were more likely to qualify for FGIDs if their parents also qualified for FGIDs ${ }^{46}$. The prevalence of FD
- post prandial distress syndrome is approximately $7 \%$ and of FD - epigastric pain syndrome it is $0.4 \%$.

\section{Sex and age}

A meta-analysis reviewing functional abdominal pain in children aged 4-18 years of age found that girls had a significant higher proportion of functional abdominal pain disorders when compared to boys $(15.9 \%$ vs. $11.5 \%$, pooled OR 1.5, 95\% CI 1.3-1.7, p < 0.01) This same study found no significant difference for their prevalence in children $<12$ years of age compared to children $\geq 12$ years old (12.4\% vs. $13.8 \%$, pooled OR 0.9 , 95\% CI $0.5-$ $1.4, \mathrm{p}=0.62)^{4}$.

Another cross-sectional study in children found that FD-epigastric pain syndrome was more prevalent in males than females subjects $(0.9 \% \text { males vs. } 0 \% \text { females, } \mathrm{p}=0.04)^{46}$. In this study, no other differences were found by sex, race, or ethnicity with regard to FAPDs $^{46}$.

\section{QUALITY OF LIFE AND COST}

Pediatric patients with FD have more dyspeptic symptoms, greater functional disability, and poorer health related quality of life when they reach adolescence (vs. healthy controls) ${ }^{47}$. Both depression and anxiety are common in this population, with anxiety being more chronic $^{47}$. FD-post-prandial distress syndrome is associated with higher anxiety and depression, whereas FD-epigastric pain is associated with lower depression rates by patient reports ${ }^{48}$. 
Sleep disturbances are highly prevalent in subjects with FGIDs compared to the rest of the population ${ }^{49}$. Sleep disturbances in patients with FD are associated with worse symptom severity and higher levels of anxiety ${ }^{50}$. A recent study in adults found that subjective sleep quality, sleep latency, sleep duration, habitual sleep efficiency, sleep disturbances, use of sleep medication, and daytime dysfunction were worse in patients with FD when compared with controls $^{51}$. The same study found that subjects with longer-term FD ( $>6$ months) had worse sleep disturbances than those with shorter-term FD, suggesting that sleep quality may deteriorate with the development of $\mathrm{FD}^{51}$.

A recent retrospective study looking to estimate the annual evaluation cost for children with FD found the cost for all patients to be $\$ 724.874 \pm \$ 180.075$. When divided into improved symptoms versus partial/no improvement in symptoms, $\$ 544.799 \pm \$ 87.995$ and $\$ 904.949 \pm 79.083$ were the costs, respectively $^{52}$. An extrapolated annual cost of evaluation in children with FD would be close to $\$ 5.8$ billion $^{52}$. As would be expected, the average number of clinic visits, use of imaging studies, and endoscopic procedures were significantly higher in patients with partial/ no improvement in symptoms ${ }^{52}$. Thus, children with FD represent a significant financial burden.

\section{TREATMENT}

Treatments for FD should be aimed to one or more of the main mechanisms: Gastric emptying, gastric accommodation, and visceral pain sensation ${ }^{53}$. Unfortunately, currently there are no prognostic factors described in the literature that help predict response to treatment in these patients ${ }^{52}$. Patient education is essential and all patients must receive psychosocial support ${ }^{1}$. Dietary changes can be implemented, including smaller meals and avoidance of fatty foods and carbonated beverages.

\section{FD-post-prandial distress syndrome}

Cyproheptadine is an antihistamine commonly used as first line in patients suspected of having FD-postprandial distress syndrome ${ }^{1}$. Not many randomized trials exist in the pediatric population assessing its use for FAPDs despite its popularity. A double-blind randomized placebo-controlled trial led by Sadeghian et al. resulted in improvement in the intensity and frequency in abdominal pain among children treated with cyproheptadine when compared to placebo $(n=29)^{54}$. Unfortunately, this study is limited by its small size and non-validated measurement tools. Further studies assessing the use of cyproheptadine are warranted.

Peppermint oil is known to relax the lower esophageal sphincter and relieve symptoms of dyspepsia and can be trialed in this population $^{55}$. If both of these options fail, prokinetics can be tried. A placebo-controlled trial using domperidone by Karunanayake et al. was able to show overall improvement (74\% domperidone vs. $50 \%$ placebo; $\mathrm{p}=$ $0.013)$, decreased severity of abdominal pain $(54 \%$ vs. $25 \% ; \mathrm{p}=0.008)$, and overall $\mathrm{im}-$ provement at the 6 months follow-up (88\% vs. $66 \% ; \mathrm{p}=0.009)^{56}$. 
Buspirone is a non-selective serotonin $5-\mathrm{HT}_{1 \mathrm{~A}}$ receptor agonist that inhibits the tone of the proximal stomach and delays gastric emptying rate in a dose dependent manner ${ }^{57}$. Buspirone has been shown to be superior to placebo in alleviating early satiation, post-prandial fullness, and upper abdominal bloating in adults with $\mathrm{FD}^{58}$. It has been trialed in children and adolescents with anxiety, proving to be generally safe and well tolerated at doses up to $30 \mathrm{mg}$ BID $^{59}$. No studies have been done to assess its use for inappropriate gastric accommodation in children.

Antiemetics such as ondansetron, diphenhydramine, and prochlorperazine can be helpful in reducing nausea but unfortunately can be sedating ${ }^{1}$. When all these treatments fail, neuromodulation and/or psychological interventions can be trialed. Modulating central pain pathways and consequently visceral hypersensitivity by the use of percutaneous electrical field stimulation (Neuro-Stim, Innovative Health Solutions, IN, USA) has been studied in randomized clinical trials. A randomized, sham-controlled trial in adolescents aged 11-18 years who met Rome III criteria for abdominal pain-related FGIDs found that Neuro-Stim had sustained efficacy for abdominal pain ${ }^{60}$. Psychological interventions include cognitive behavioral therapy, hypnotherapy (including guided imagery), yoga, and written self-disclosures.

\section{FD-Epigastric pain syndrome}

Proton pump inhibitors (PPIs) are usually the first line therapy for this population ${ }^{1}$. PPIs have shown to be effective and well tolerated in randomized placebo-controlled trials in adults with $\mathrm{FD}^{61,62}$. In children, only limited studies are available. Even though they have shown to be safe and well-tolerated short term in pediatric patients, PPIs used for long- term has shown to lead to biochemical, endoscopic and histological changes, and small bacterial overgrowth ${ }^{62}$. In children with FD, two clinical studies by Dehgani et al. (2011, n = 169) and See et al. (2001, n = 25) showed improvement in dyspeptic symptoms when using these medications (vs. placebo). However, these studies showed significant methodological flaws and heterogeneity, and thus results should be interpreted with caution $^{63}$. Of the PPIs, omeprazole seems to be the most effective ${ }^{63}$.

Even though limited data shows improvement in symptoms of FD with PPIs, longitudinal studies are warranted. These medications should be prescribed with caution and physicians should perform regular assessment of the ongoing need for this medication.

If PPIs fail to resolve symptoms, subsequent therapies include cyproheptadine, herbal medications, or medications aimed on altering stomach sensitivity and accommodation, as stated above. Neuromodulation and psychological techniques are also indicated.

\section{CONCLUSION}

FD represents a difficult to manage entity in children. The extrapolation of adult data and lack of pediatric-specific data represents a limitation to treatment options. The medical, social, and economic impact of FD is rising, 
affecting not only the child but the child's family. As Lu and Saps state, "Despite all we have learned during the past four decades, it is hard to argue that we are truly making progress"64. Given what we know now as plausible early causes of functional abdominal pain disorders (disruption of the gut microbiota, early life events that lead to hyperalgesia such as cow's milk protein), maybe we should shift our focus towards prevention and try to better understand the epidemiology and pathophysiology of functional abdominal pain disorders.

\section{FUNDING}

The author received funding from the American Neurogastroenterology and Motility Society.

\section{CONFLICTS OF INTEREST}

None.

\section{ETHICAL DISCLOSURES}

\section{Protection of human and animal subjects.} The authors declare that no experiments were performed on humans or animals for this study.

Confidentiality of data. The authors declare that no patient data appear in this article.

Right to privacy and informed consent. The authors declare that no patient data appear in this article.

\section{REFERENCES}

1. Thapar N, Benninga MA, Crowell MD, di Lorenzo C, Mack I, Nurko S, et al. Paediatric functional abdominal pain disorders. Nat Rev Dis Primers. 2020;6:89

2. Romano C, Valenti S, Cardile S, Benninga MA. Functional dyspepsia: an enigma in a conundrum. J Pediatr Gastroenterol Nutr. 2016;63:579-84.

3. Talley NJ. Functional dyspepsia: new insights into pathogenesis and therapy. Korean J Intern Med. 2016;31:444-56

4. Korterink JJ, Diederen K, Benninga MA, Tabbers MM. Epidemiology of pediatric functional abdominal pain disorders: a meta-analysis. PLoS One. 2015;10:e126982.

5. Fang YJ, Liou JM, Chen CC, Lee JY, Hsu YC, Chen MJ, et al. Distinct aetiopathogenesis in subgroups of functional dyspepsia according to the Rome III criteria. Gut. 2015;64:1517-28.

6. Futagami S, Yamawaki H, Agawa S, Higuchi K, Ikeda G, Noda H, et al. New classification Rome IV functional dyspepsia and subtypes. Transl Gastroenterol Hepatol. 2018;3:70.

7. Bisschops R, Tack J. Dysaccommodation of the stomach: therapeutic nirvana? Neurogastroenterol Motil. 2007;19:85-93.

8. Tack J, Camilleri M. New developments in the treatment of gastroparesis and functional dyspepsia. Curr Opin Pharmacol. 2018;43:111-7.

9. Orthey P, Yu D, van Natta ML, Ramsey FV, Diaz JR, Bennett PA, et al. Intragastric meal distribution during gastric emptying scintigraphy for assessment of fundic accommodation: correlation with symptoms of gastroparesis. J Nucl Med. 2018;59:691-7.

10. Talley NJ. Functional dyspepsia: advances in diagnosis and therapy. Gut Liver. 2017;11:349-57.

11. Singh V, Singh M, Schurman JV, Friesen CA. Histopathological changes in the gastroduodenal mucosa of children with functional dyspepsia. Pathol Res Pract. 2018;214:1173-8.

12. Hyams JS, di Lorenzo C, Saps M, Shulman RJ, Staiano A, van Tilburg M. Functional disorders: children and adolescents. Gastroenterology. 2016;15:00181-5.

13. Saps M, Velasco-Benitez CA, Langshaw AH, Ramírez-Hernández CR Prevalence of functional gastrointestinal disorders in children and adolescents: comparison between Rome III and Rome IV criteria. J Pediatr. 2018;199:212-6.

14. Dhroove G, Chogle A, Saps M. A million-dollar work-up for abdominal pain: is it worth it? J Pediatr Gastroenterol Nutr. 2010;51:579-83.

15. Llanos-Chea A, Saps M. Utility of diagnostic tests in children with functional abdominal pain disorders. Gastroenterol Hepatol (NY). 2019;15:41422.

16. Mani J, Madani S. Pediatric abdominal migraine: current perspectives on a lesser known entity. Pediatric Health Med Ther. 2018;9:47-58.

17. Korterink J, Devanarayana NM, Rajindrajith S, Vlieger A, Benninga MA Childhood functional abdominal pain: mechanisms and management. Nat Rev Gastroenterol Hepatol. 2015;12:159-71.

18. Bonilla S, Saps M. Early life events predispose the onset of childhood functional gastrointestinal disorders. Rev Gastroenterol Mex. 2013;78:82-91.

19. Miranda A, Peles S, Shaker R, Rudolph C, Sengupta JN. Neonatal nociceptive somatic stimulation differentially modifies the activity of spinal neurons in rats and results in altered somatic and visceral sensation. J Physiol. 2006;572:775-87.

20. Carbone F, Tack J, Hoffman I. The intragastric pressure measurement: a novel method to assess gastric accommodation in functional dyspepsia children. J Pediatr Gastroenterol Nutr. 2017;64:918-24.

21. Wilder-Smith CH, Li X, Shen L, Cao Y, Ho KY, Wong RK. Dysfunctional endogenous pain modulation in patients with functional dyspepsia. Neurogastroenterol Motil. 2014;26:489-98.

22. Wilder-Smith $\mathrm{CH}$. The balancing act: endogenous modulation of pain in functional gastrointestinal disorders. Gut. 2011;60:1589-99. 
23. Devanarayana NM, Rajindrajith S, Rathnamalala N, Samaraweera S, Benninga MA. Delayed gastric emptying rates and impaired antral motility in children fulfilling Rome III criteria for functional abdominal pain. Neurogastroenterol Motil. 2012;24:420-5, e207.

24. Devanarayana NM, Rajindrajith S, Perera MS, Nishanthanie SW, Benninga MA. Gastric emptying and antral motility parameters in children with functional dyspepsia: association with symptom severity. J Gastroenterol Hepatol. 2013;28:1161-6.

25. Devanarayana NM, Rajindrajith S, Bandara C, Shashiprabha G, Benninga MA. Ultrasonographic assessment of liquid gastric emptying and antral motility according to the subtypes of irritable bowel syndrome in children. J Pediatr Gastroenterol Nutr. 2013;56:443-8.

26. Hoffman I, Tack J. Assessment of gastric motor function in childhood functional dyspepsia and obesity. Neurogastroenterol Motil. 2012;24:10812, e81.

27. Arakawa T, Uno H, Fukuda T, Higuchi K, Kobayashi K, Kuroki T. New aspects of gastric adaptive relaxation, reflex after food intake for more food: involvement of capsaicin-sensitive sensory nerves and nitric oxide. J Smooth Muscle Res. 1997;33:81-8.

28. Carbone F, Verschueren S, Rotondo A, Tack J. Duodenal nutrient exposure contributes to enhancing gastric accommodation. Neurogastroenterol Motil. 2019;31:e13697

29. Hoffman I, Vos R, Tack J. Assessment of gastric sensorimotor function in paediatric patients with unexplained dyspeptic symptoms and poor weight gain. Neurogastroenterol Motil. 2007;19:173-9.

30. Cucchiara S, Minella R, Iorio R, Emiliano M, Az-Zeqeh N, Vallone G, et al. Real-time ultrasound reveals gastric motor abnormalities in children investigated for dyspeptic symptoms. J Pediatr Gastroenterol Nutr. 1995;21: 446-53.

31. Olafsdottir E, Gilja OH, Aslaksen A, Berstad A, Fluge G. Impaired accommodation of the proximal stomach in children with recurrent abdominal pain. J Pediatr Gastroenterol Nutr. 2000;30:157-63.

32. Cucchiara S, Riezzo G, Minella R, Pezzolla F, Giorgio I, Auricchio S. Electrogastrography in non-ulcer dyspepsia. Arch Dis Child. 1992;67:613-7.

33. Gill SR, Pop M, Deboy RT, Eckburg PB, Turnbaugh PJ, Samuel BS, et al. Metagenomic analysis of the human distal gut microbiome. Science. 2006;312:1355-9.

34. Llanos-Chea A, Fasano A. Gluten and functional abdominal pain disorders in children. Nutrients. 2018;10:1491

35. Robinson JO, Alverez JH, Dodge JA. Life events and family history in children with recurrent abdominal pain. J Psychosom Res. 1990;34:171-81.

36. Shava U, Srivastava A, Mathias A, Kumar N, Yachha SK, Gambhir S, et al. Functional dyspepsia in children: a study of pathophysiological factors. J Gastroenterol Hepatol. 2021;36:680-6.

37. Devanarayana NM, Rajindrajith S, Perera MS, Nishanthanie SW, Karunanayake A, Benninga MA. Association between functional gastrointestinal diseases and exposure to abuse in teenagers. J Trop Pediatr. 2014;60: 386-92.

38. Campo JV, Bridge J, Ehmann M, Altman S, Lucas A, Birmaher B, et al. Recurrent abdominal pain, anxiety, and depression in primary care. Pediatrics. 2004;113:817-24.

39. Chang L. The role of stress on physiologic responses and clinical symptoms in irritable bowel syndrome. Gastroenterology. 2011;140:761-5.

40. Walker LS, Smith CA, Garber J, Claar RL. Appraisal and coping with daily stressors by pediatric patients with chronic abdominal pain. J Pediatr Psychol. 2007;32:206-16.

41. Campo JV, Bridge J, Lucas A, Savorelli S, Walker L, di Lorenzo C, et al. Physical and emotional health of mothers of youth with functional abdominal pain. Arch Pediatr Adolesc Med. 2007;161:131-7.

42. Camilleri M. Leaky gut: mechanisms, measurement and clinical implications in humans. Gut. 2019;68:1516-26.

43. Camilleri M, Madsen K, Spiller R, Greenwood-van Meerveld B, van Meerveld BG, Verne GN. Intestinal barrier function in health and gastrointestinal disease. Neurogastroenterol Motil. 2012;24:503-12.
44. Du LJ, Chen BR, Kim JJ, Kim S, Shen JH, Dai N. Helicobacter pylori eradication therapy for functional dyspepsia: systematic review and meta-analysis. World J Gastroenterol. 2016;22:3486-95.

45. Kourikou A, Karamanolis GP, Dimitriadis GD, Triantafyllou K. Gene polymorphisms associated with functional dyspepsia. World J Gastroenterol. 2015;21:7672-82.

46. Robin SG, Keller C, Zwiener R, Hyman PE, Nurko S, Saps M, et al. Prevalence of pediatric functional gastrointestinal disorders utilizing the Rome IV criteria. J Pediatr. 2018;195:134-9.

47. Rippel SW, Acra S, Correa H, Vaezi M, di Lorenzo C, Walker LS. Pediatric patients with dyspepsia have chronic symptoms, anxiety, and lower quality of life as adolescents and adults. Gastroenterology. 2012;142:754-61.

48. Schurman JV, Singh M, Singh V, Neilan N, Friesen CA. Symptoms and subtypes in pediatric functional dyspepsia: relation to mucosal inflammation and psychological functioning. J Pediatr Gastroenterol Nutr. 2010;51:298-303.

49. Koloski NA, Jones M, Walker MM, Keely S, Holtmann G, Talley NJ. Sleep disturbances in the irritable bowel syndrome and functional dyspepsia are independent of psychological distress: a population-based study of 1322 Australians. Aliment Pharmacol Ther. 2021;54:627-36.

50. Lacy BE, Everhart K, Crowell MD. Functional dyspepsia is associated with sleep disorders. Clin Gastroenterol Hepatol. 2011;9:410-4.

51. Huang ZP, Li SM, Shen T, Zhang YY. Correlation between sleep impairment and functional dyspepsia. J Int Med Res. 2020;48:300060520937164.

52. Mani J, Madani S, Thomas R. Economic impact and prognostic factors of functional dyspepsia in children. J Pediatr Gastroenterol Nutr. 2020;70:e65-70.

53. Santucci NR, Saps M, van Tilburg MA. New advances in the treatment of paediatric functional abdominal pain disorders. Lancet Gastroenterol Hepatol. 2020;5:316-28.

54. Sadeghian M, Farahmand F, Fallahi GH, Abbasi A. Cyproheptadine for the treatment of functional abdominal pain in childhood: a double-blinded randomized placebo-controlled trial. Minerva Pediatr. 2008;60:1367-74.

55. Kline RM, Kline JJ, di Palma J, Barbero GJ. Enteric-coated, pH-dependent peppermint oil capsules for the treatment of irritable bowel syndrome in children. J Pediatr. 2001;138:125-8.

56. Karunanayake A, Devanarayana NM, de Silva A, Gunawardena S, Rajindrajith S. Randomized controlled clinical trial on value of domperidone in functional abdominal pain in children. J Pediatr Gastroenterol Nutr. 2018;66:725-31.

57. Miwa H, Nagahara A, Tominaga K, Yokoyama T, Sawada Y, Inoue K, et al Efficacy of the 5-HT1A agonist tandospirone citrate in improving symptoms of patients with functional dyspepsia: a randomized controlled trial. Am J Gastroenterol. 2009;104:2779-87.

58. Tack J, Janssen P, Masaoka T, Farré R, van Oudenhove L. Efficacy of buspirone, a fundus-relaxing drug, in patients with functional dyspepsia. Clin Gastroenterol Hepatol. 2012;10:1239-45.

59. Salazar DE, Frackiewicz EJ, Dockens R, Kollia G, Fulmor IE, Tigel PD, et al. Pharmacokinetics and tolerability of buspirone during oral administration to children and adolescents with anxiety disorder and normal healthy adults. J Clin Pharmacol. 2001;41:1351-8.

60. Kovacic K, Hainsworth K, Sood M, Chelimsky G, Unteutsch R, Nugent M, et al. Neurostimulation for abdominal pain-related functional gastrointestinal disorders in adolescents: a randomised, double-blind, sham-controlled trial. Lancet Gastroenterol Hepatol. 2017;2:727-37.

61. Wang WH, Huang JQ, Zheng GF, Xia HH, Wong WM, Liu XG, et al. Effects of proton-pump inhibitors on functional dyspepsia: a meta-analysis of randomized placebo-controlled trials. Clin Gastroenterol Hepatol. 2007;5:178-85; quiz 40.

62. Laine L, Nagar A. Long-term PPI use: balancing potential harms and documented benefits. Am J Gastroenterol. 2016;111:913-5.

63. Browne PD, Nagelkerke SC, van Etten-Jamaludin FS, Benninga MA, Tabbers MM. Pharmacological treatments for functional nausea and functional dyspepsia in children: a systematic review. Expert Rev Clin Pharmacol. 2018;11:1195-208.

64. Lu PL, Saps M. Functional gastrointestinal disorders: all roads lead to prevention. Clin Gastroenterol Hepatol. 2018;16:814-6. 